Review Article

\title{
Microbiome and Asthma: What Have Experimental Models Already Taught Us?
}

\author{
R. Bonamichi-Santos, M. V. Aun, R. C. Agondi, J. Kalil, and P. Giavina-Bianchi \\ Clinical Immunology and Allergy Division, University of São Paulo School of Medicine, 01454-010 São Paulo, SP, Brazil \\ Correspondence should be addressed to P. Giavina-Bianchi; pbianchi@usp.br
}

Received 9 May 2015; Accepted 2 July 2015

Academic Editor: Kurt Blaser

Copyright ( 2015 R. Bonamichi-Santos et al. This is an open access article distributed under the Creative Commons Attribution License, which permits unrestricted use, distribution, and reproduction in any medium, provided the original work is properly cited.

Asthma is a chronic inflammatory disease that imposes a substantial burden on patients, their families, and the community. Although many aspects of the pathogenesis of classical allergic asthma are well known by the scientific community, other points are not yet understood. Experimental asthma models, particularly murine models, have been used for over 100 years in order to better understand the immunopathology of asthma. It has been shown that human microbiome is an important component in the development of the immune system. Furthermore, the occurrence of many inflammatory diseases is influenced by the presence of microbes. Again, experimental models of asthma have helped researchers to understand the relationship between the microbiome and respiratory inflammation. In this review, we discuss the evolution of murine models of asthma and approach the major studies involving the microbiome and asthma.

\section{Introduction}

Asthma is a common and potentially serious chronic inflammatory disease that imposes a substantial burden on patients, their families, and the community [1]. It is recognized as a complex disease with a heterogeneous profile divided into phenotypes. The phenotypes can be distinguished by their pathology, immunology, clinical manifestations, response to treatments, and long-term outcomes [2]. Asthma is one of the most common chronic diseases worldwide and its global economic cost exceeds those of tuberculosis and HIV/AIDS combined [3, 4]. Globally, about 300 million people are currently receiving treatment for the disease.

Unfortunately, 5 to $10 \%$ of patients present severe asthma, which remains uncontrolled despite high doses of inhaled corticosteroid combined with long-acting beta-agonists [5]. Even corresponding with a small proportion of patients, severe asthma represents the majority of asthma-related deaths and almost half of the total healthcare costs associated with the disease $[6,7]$.

Less than $12 \%$ of drugs developed for use in humans are successfully registered and there are still high costs for developing these drugs to enter the market $[8,9]$. Experimental models are important for the study of asthma immunopathogenesis and as a template for new therapies development.

\section{Experimental Models in Asthma}

There are three types of experimental models in asthma that are frequently used in research: in silico, in vitro, and in vivo. In silico models are performed on computers and can simulate diseases and generate virtual patients. Human cells can be studied in vitro in physiological and pathological conditions. However, this model is not suitable to assess environment influences and long-term effects. The third and most commonly used type of experimental model in asthma is in vivo model, particularly the murine model.

\section{In Vivo Asthma Models}

Animal models have been used for over 100 years in mechanistic studies, increasing the scientific knowledge of asthma [10]. Researchers have studied abnormalities which are characteristic of asthma, such as airway flow limitation, inflammation, and remodeling. Animal models allow us to test the efficacy of a particular drug as well as its toxicity 
before starting clinical trials for safety and efficacy in humans. However, the interpretation and extrapolation of the results originating from such models for patients with asthma are highly dependent on the outcome of interest and animal species chosen in the experimental model [11].

No experimental animal is known to spontaneously develop a disease with characteristics that can be considered to be asthma [12]. However, there are some examples of asthma-like disease in the animal kingdom: cats can present a bronchial disease that is similar to human chronic asthma [13] and horses can develop a neutrophil dominated airway disease known as "heaves" that has some of the hallmarks of asthma [14].

The development of animal models of allergic asthma involves sensitization of the animal to an antigen of interest and subsequently challenge of the airways, triggering an allergic response [14]. Many species are used as models of asthma, such as guinea pig, rat, and mouse, which are the most commonly used. Unfortunately, none of them can be considered an ideal murine model [15].

Guinea pigs are able to cough and sneeze, and pulmonary changes presented by them after exposure to allergens are similar to changes in FEV1 after bronchial challenge in humans. Furthermore, the lung anatomy of guinea pigs is more similar to human lung compared to mice. On the other hand, transgenic or knockout animals are not available and reagents have restricted availability. In addition, sensitization of airways and response to allergen may vary over time and between laboratories and depending on the source of animals $[15,16]$.

Rats have some advantage over mice for the study of inhaled agents, but again reagents and transgenic or knockout animals are not readily available. The airway response to allergens may vary over time and there are also variations between different laboratories and animal sources $[15,16]$.

Mice are relatively easy to create and procreation is fast. In addition, chemical reagents are widely available, as well as knockout animals and transgenic strains. Unfortunately, it is difficult to extrapolate doses of inhaled allergen from mouse models to humans. In addition, lung anatomy of these animals is very different from human lung (e.g., small size, less bifurcations), as well as lung biology/pharmacology (e.g., absence of $\beta 2$-adrenergic receptors in the smooth muscle of mice airway) $[15,16]$.

\section{Research on Mice Models of Asthma}

Mice have become the most commonly used species because they are easier to create, procreate, maintain, and handle. There is a wide variety of reagents available for determination of antibodies and cytokines, as well as transgenic or knockout strains, which are used to study the mechanisms of immune diseases [15].

There are well-documented differences in lung anatomy/ histology of humans and mice, such as the organ location, branching airways, blood supply, smooth muscle, and cell types. These factors can affect the inflammatory response and lung function that are regularly evaluated in asthma studies [16-18].
Many questions about human asthma are still unanswered. There is a broad understanding of the Th2 response in atopic asthma, but researchers still do not understand what happens to about $50 \%$ of patients with nonallergic asthma [19]. Furthermore, there are few therapeutic options available for the treatment of patients who do not respond to inhaled corticosteroids (ICS) [20]. It is urgent to understand the Th2low subsets, noneosinophilic asthma [21] and develop therapies for these patients, especially for those with severe asthma $[22,23]$. Good murine models of nonallergic asthma are still missing. In this context, more translational studies must be done and new experimental models must be developed [24].

Asthma mouse models have changed significantly since the 1990s. Latest models assessed the role of relevant risk factors and evaluated potential drug targets. Furthermore, studies have demonstrated the role of various cells and tissues in lung inflammation, including the complex interaction between the immune system, neural networks, and structural components of the respiratory system [25].

Since the traditional experimental models of allergen sensitization by injection are not similar to human disease, some newer models have been developed mimicking how real-world asthma occurs. To investigate the response to continuous antigen exposure, similar to human disease, mice were exposed to extracts of house dust mites (HDM) or ovalbumin (OVA) intranasally for five consecutive days, followed by 2 days of rest, for seven consecutive weeks [26]. Continuous exposure to HDM, unlike OVA, caused serious and persistent eosinophilic inflammation. Histological analysis of the lungs showed evidence of airway remodeling in mice exposed to HDM, with goblet cell hyperplasia, collagen deposition, and peribronchial contractile tissue accumulation. After 9 weeks without HDM exposure, inflammation of the airways completely resolved and airway hyperresponsiveness partially improved, but remodeling had not changed [26].

Currently, there is a wide range of murine models of asthma, with different underlying pathological mechanisms ranging from nonatopic disease to transgenic models. Models with overexpression of the Th2-specific transcription factor GATA3 or the Th17-transcription factor ROR $\gamma$ t provide methods for studying in vivo the role of Th2 and Th17 immune response in allergic airway disease, respectively [27, 28].

These new mouse models have also become appreciated as being more complex, with mixed airway granulocytic infiltrate (eosinophilic and neutrophilic), covering the immune responses of Th2 and Th17 profile. It has been demonstrated that the pathogenicity of asthma can include the Th17 response [29]. The neutrophilic models allowed researchers to elucidate different underlying mechanisms in a disease with lower sensitivity to corticosteroids [27, 30, 31]. Thus, availability of animal models with different phenotypes and endotypes of asthma will provide the development of better treatments for humans with nonclassical atopic disease [25].

\section{Microbiome and Asthma}

The immune system is linked to the human ecosystem, which includes $10^{13}-10^{14}$ bacteria [32]. Joshua Lederberg 
coined the term "microbiome" and described the microflora as part of the human metabolism. The human microbiome includes all bacteria, not only in the intestine, but also in the upper and lower respiratory tract, skin, and urinary tract. Since 2007, the Human Microbiome Project (HMP) from the National Institutes of Health (NIH) and the European Program Metagenomics of the Human Intestinal Tract (MetaHit Consortium) has sequenced the genomes of all organisms inhabiting the human body.

The relationship between exposure to microbes and asthma continues to stimulate scientific interest. Both human epidemiological and animal experimental studies have been done to better understand the interaction between the microbiome and the chronic allergic respiratory disease. Regarding human asthma, both the role of exposure to microbes in early life and the impact of bacteria colonization or infection in patients already diagnosed with asthma have been investigated [33-44].

It is important to distinguish the bacteria accurately to understand the relationship between microbiome and immune response. The diversity of known bacteria is enormous and each biological effect in respiratory disease is probably species specific.

Well-developed techniques focused on studies of bacteria are based on analysis of the 16S ribosomal RNA (rRNA) gene. This gene has properties that facilitate bacterial community analysis, such as the presence of broadly conserved sequences that flank a number of hypervariable regions. There are several higher resolution molecular tools to study the $16 \mathrm{~S}$ rRNA diversity, including microarray phylogenetic analysis and next generation sequencing-based approaches [45-50].

\section{Environmental Microbiome and Asthma}

Environmental factors have been associated with either risk or protection for allergic sensitization and asthma. Exposure to farm animals [51-56] and raw milk consumption have been associated with decreased atopic disease development in childhood [57]. Moreover, antibiotic use during pregnancy or the first year of life has been associated with increased risk for the development of asthma [12], and Gram-negative bacteria endotoxin levels in mattress dust are inversely related to sensitization and atopic asthma in children [58]. Schaub et al., studying 84 pregnant women, noted that exposure to microbes in the prenatal period was associated with increase of Treg cells with higher expression of FoxP3 and lower secretion of Th2 cytokines in umbilical cord blood [59]. Thus normal microbiota environmental stimuli shape the expression of host genes and/or immune responses, even without modifications in the composition of the host microbiota.

\section{Gut Microbiome and Asthma}

The microbiota is an antigenic stimulus that assists in the development of the immune system in early life $[54,55]$. The composition of the intestinal microbiota plays an important role in defining the phenotype of the immune response [5659]. Different species within a particular bacterial family can also have different immune-stimulating effects, as reported in the case of bifidobacteria and lactobacilli $[47,60]$. It has been shown that, among breast-fed infants, Bifidobacterium bifidum was the main Bifidobacterium species found in fecal specimens from nonallergic infants, while $B$. adolescentis and $B$. longum were more prevalent in those who developed allergy [47]. These data show that each bacterial species has a different interaction with the immune system.

Bacterial species or bacterial diversity in the gut may be implicated in the development of asthma. In a prospective study of 117 children classified by the Asthma Predictive Index (API), fecal samples taken at three weeks of age showed a higher prevalence of Bacteroides fragilis and other anaerobic bacteria in the API-positive in comparison with the APInegative group [48]. In a birth cohort study of 411 children at high risk for asthma, stool samples collected at one and twelve months after birth were analyzed by $16 \mathrm{~S}$ rRNA-based denaturing gradient gel electrophoresis (DGGE). Reduced bacterial diversity was inversely associated with allergic sensitization in the first six years of life, though not with the development of asthma [38]. Evidence from studies of the environment and intestinal flora indicates that the reduction of exposure to a variety of microbes, including specific microbial consortia, has negative implications for the health of the immune system that includes risk for allergy and asthma [61].

\section{Respiratory Microbiome and Asthma}

The idea that bronchial infection may underlie asthma was fostered by epidemiological studies that have reported an association between community outbreaks of Chlamydophila pneumoniae and the occurrence of late-onset asthma [62]. Analyses of sequencing techniques based on microarray and $16 \mathrm{~S}$ rRNA are able to define the profile of the flora in asthmatic airways. Studies have shown that the composition of the bacterial microflora detected from the lower respiratory tract differs in persons with asthma compared to healthy individuals $[43,44,63]$.

The predominant bacterial communities associated with asthma were mostly represented by groups of bacteria that are not members of the dominant oral microbiome [43, 63]. The members of the phylum Proteobacteria, in particular Haemophilus spp., have been more commonly identified from bronchial brushing or lavage from individuals with airway disease. Members of the phylum Bacteroidetes, such as Prevotella spp., were more often found in samples from healthy individuals. Specific bacterial families observed more frequently among patients with asthma include Enterobacteriaceaeand Neisseriaceae [63]. However, some bacteria may have protective effects. For example, nasal administration of Lactobacillus rhamnosus induced protection against respiratory syncytial virus infection in mice [64].

Recently, a study analyzing the fungal composition of induced sputum samples showed several differences in species composition between asthma patients and 
TABLE 1: Microbial exposures and asthma.

\begin{tabular}{|c|c|c|c|c|}
\hline Exposure & Microbial exposure assessment & Effect & Endpoint & References \\
\hline \multirow{6}{*}{ Environment } & $\begin{array}{l}\text { Exposure to animals (dogs, cats, } \\
\text { and farm animals) }\end{array}$ & Decrease & Allergy or asthma & {$[51-56]$} \\
\hline & Raw milk consumption & Decrease & Atopy or asthma in childhood & {$[57]$} \\
\hline & $\begin{array}{l}\text { Antibiotic use during pregnancy } \\
\text { or first year of life }\end{array}$ & Increase & Risk of asthma & {$[42]$} \\
\hline & $\begin{array}{l}\text { Gram-negative bacteria's } \\
\text { endotoxin levels in mattress dust }\end{array}$ & Inverse relation & $\begin{array}{l}\text { Atopic asthma and sensitization } \\
\text { in children }\end{array}$ & {$[58]$} \\
\hline & \multirow[t]{2}{*}{ Prenatal microbial exposure } & Increase & $\begin{array}{l}\text { Cord blood } \\
\text { Treg cell counts } \\
\text { FOXP3 expression }\end{array}$ & \multirow[t]{2}{*}[59]{} \\
\hline & & Decrease & TH2 cytokine secretion & \\
\hline \multirow{4}{*}{ Digestive tract } & Bifidobacterium bifidum & More prevalent & $\begin{array}{l}\text { Stool samples of nonallergic } \\
\text { infants }\end{array}$ & \multirow[t]{2}{*}[47]{} \\
\hline & $\begin{array}{l}\text { Bifidobacterium adolescentis and } \\
\text { B. longum }\end{array}$ & More prevalent & Stool samples of allergic infants & \\
\hline & Bacteroides fragilis & High prevalence & $\begin{array}{l}\text { Stool samples of children with } \\
\text { positive prediction for asthma }\end{array}$ & {$[48]$} \\
\hline & Bacterial diversity & Inverse association & Allergic sensitization & {$[38]$} \\
\hline \multirow{6}{*}{ Respiratory tract } & $\begin{array}{l}\text { Bronchial infection by } \\
\text { Chlamydophila pneumonia }\end{array}$ & Association & Asthma development & {$[40]$} \\
\hline & $\begin{array}{l}\text { Microbiota species in lower } \\
\text { respiratory tract }\end{array}$ & Different & Asthmatic versus healthy subjects & {$[43,44,63]$} \\
\hline & Haemophilus spp. in airways & More frequent & Subjects with airway diseases & \multirow{2}{*}[63]{} \\
\hline & Prevotella spp.in airways & More frequent & Healthy subjects & \\
\hline & $\begin{array}{l}\text { Enterobacteriaceae and } \\
\text { Neisseriaceae }\end{array}$ & More frequent & Asthmatic patients & {$[63]$} \\
\hline & Malassezia pachydermatis & Frequent & Asthmatic patients & {$[65]$} \\
\hline
\end{tabular}

controls [65]. Malassezia pachydermatis, a fungus that was previously associated with atopic dermatitis, was one of the fungi most frequently found in samples of asthmatic patients. However, this finding is not detrimental and there is a need for more studies regarding fungal sequence databases. So far, the role of fungal colonization in asthma is still unclear [66].

As clinical trials assessing microbiome and human asthma are still not available, data from animal models are the basis for better understanding the role of bacteria in the respiratory disease. Data available regarding the interaction between the microbiome and human asthma are summarized in Table 1.

\section{Animal Models and the Microbiome}

Recent studies in animal models demonstrate that gut microbiota is an important driver of immune response that can modulate allergic inflammation in the airways and features of asthma [67-69]. The germ-free mice compared to specific pathogen-free mice exhibit increased accumulation of mucosal invariant natural killer T cells (iNKT) in the colonic lamina propria as well as in the lung. These germ-free mice, in an ovalbumin model of allergic asthma, presented increased airway resistance and eosinophils count in bronchoalveolar lavage and tissue. Feeding neonate germ-free mice with conventional microbiota, but not adults, minimized the accumulation of iNKT cells in the lungs and attenuated allergic inflammation and asthma [67]. In another study, vancomycin administration to neonatal mice led to reduced bacterial diversity and similar increased susceptibility to allergic asthma in a murine model [69].

Several studies have demonstrated that oral administration of bacterial species with immunomodulating properties can modulate features of allergic asthma in the lungs. Oral supplementation with Bifidobacterium species and specific Lactobacillus led to reduced production of Th2 cytokines and eosinophilic inflammation and promoted Treg and Th17 populations [68-73].

The probiotic Lactococcus lactis has been used in a model of asthma induced by HDM and induced inhibition of Th2 population, preventing the development of allergic inflammation [74]. Findings of these and other studies suggest that interventions in intestinal microbiome during a specific period of time may alter susceptibility or attenuate allergic asthma.

Heat-shock protein X (HspX) purified from Mycobacterium tuberculosis shifted the immune response to the Th1 profile in a mouse model of OVA-induced asthma. Furthermore, HspX enhanced OVA-induced decrease of regulatory 
TABLE 2: Models of asthma and microbiome.

\begin{tabular}{lllll}
\hline Mice strain/antigen & Microbial or exposure evaluation & Effect & Endpoint & References \\
\hline C57BL/6/nonantigen & Germ-free mice & Increase & Airway resistance and eosinophils in airways \\
\hline C57BL/6/OVA & Vancomycin to neonatal mice & $\begin{array}{l}\text { Decrease } \\
\text { Increase }\end{array}$ & $\begin{array}{l}\text { Bacterial diversity } \\
\text { Inflammation in allergic asthma }\end{array}$ \\
\hline BALB/c/OVA & $\begin{array}{l}\text { Oral supplementation with } \\
\text { Lactobacillus reuteri }\end{array}$ & Decrease & Allergic airway response & [69] \\
\hline BALB/c/OVA & $\begin{array}{l}\text { Oral supplementation with } \\
\text { Bifidobacterium longum }\end{array}$ & Decrease & Inflammation in allergic asthma \\
\hline BALB/c/OVA & $\begin{array}{l}\text { Oral supplementation with } \\
\text { Enterococcus faecalis FK-23 }\end{array}$ & Suppression & Th17 immune response \\
\hline BALB/c/HDM & Lactococcus lactis & Inhibition & Th2 response & [70] \\
\hline BALB/c/OVA & $\begin{array}{l}\text { Heat-shock protein X (HspX) } \\
\text { purified from Mycobacterium } \\
\text { tuberculosis }\end{array}$ & Regulation & Th1 immune response \\
\hline BALB/c/OVA & BCG & Decrease & $\begin{array}{l}\text { Specific-IgE levels, eosinophil, neutrophil, and } \\
\text { lymphocyte counts in BAL }\end{array}$ \\
\hline BALB/c/OVA & BCG and interleukin-12 vaccination & Decrease & Allergic airway inflammation \\
\hline BALB/c/OVA & Killed Streptococcus pneumoniae & Protection & Asthma \\
\hline
\end{tabular}

T cells in the mediastinal lymph nodes. These findings could provide new insights into the immunotherapeutic role of HspX with respect to its effects on a murine model of asthma [75].

Administration of Bacillus Calmette-Guérin (BCG) in models of asthma led to significant decrease in the levels of OVA-specific IgE, eosinophils in lung tissue, and eosinophils, neutrophils, and lymphocytes in bronchoalveolar lavage [76]. Moreover, BCG resulted in a significant increase in lung compliance and conductance in the OVA-plus-BCG group [76]. Combined BCG vaccine with interleukin-12 had an even greater impact than the BCG alone in the experimental allergic inflammation of the airways [77].

Colonization with Streptococcus pneumoniae (S. pneumoniae) is associated with an increased risk for recurrent wheeze and asthma. But killed S. pneumoniae showed some potential as an effective immunomodulatory therapy in a murine model of asthma [78]. We summarized the results of studies assessing interaction between bacterial agents or antibiotic exposure and murine models of asthma in Table 2.

More than 30 studies were published on animal models exploring helminthic infection as a protective factor against allergy. The majority of these experiments, which were conducted with a wide range of hypersensitivity models (17 of them were on asthma models), demonstrated that helminths protect against development of allergic disease. In 26 studies, the effect of helminthic infection after sensitization was analyzed. In four other studies, animals were previously infected with helminths and then sensitized. Two out of these 4 studies showed evidences of protection [79]. Other studies were performed with helminth antigens; pseudocoelomic fluids, excretory-secretory products, and whole-worm antigen preparations were capable of protecting the host against the development of allergy. Unfortunately 2 prospective doubleblind trials of helminth infection and allergic disease in human subjects did not show benefits [79].
Finally, a study recently published [80] showed that exposure to house dust mite in early life influences the lung microbiome establishment in a BALB/c model of respiratory allergic disease. Changes in lung bacterial load and community composition after birth were associated with decreased airway responses to aeroallergen exposure [80]. Interestingly, this tolerance was not associated with the existing presence of high numbers of regulatory $\mathrm{T}$ cells in the lung at birth, but rather with the development of a different $\mathrm{T}$ regulatory cell subset that seemed to require microbial presence during a critical early window after birth. These findings suggest that establishment of a lung microbiome occurs and is a dynamic process after normal birth and that the relationship between microbiota and lung-specific immune development is not static.

\section{Conclusion}

The number of publications regarding microbiome association with asthma and allergy has been rising significantly in the last years, but differences in sampling methods, experimental protocols, and bioinformatic data analysis hamper comparisons.

The patient airway microbiome includes species with pathogenic potential, as well as species with potential immunomodulatory or metabolic properties relevant to asthma specific mechanisms. The interdependency of bacterial, viral, and fungal challenges and the bidirectional crosstalk with the human immune system seems too extensive. A better understanding of the human microbiome and its impact on the host health status might lead to more effective strategies in disease prevention and treatment.

\section{Disclosure}

This paper has been read and approved by all the coauthors. 


\section{Conflict of Interests}

The authors declare that no conflict of interests exists regarding this paper's publication.

\section{Authors' Contribution}

All authors were responsible for the following: (1) substantial contributions to conception of the study, (2) drafting the paper and revising it critically for important intellectual content, and (3) final approval of the version to be published.

\section{References}

[1] Global Initiative for Asthma, "Global strategy for asthma management and prevention," GINA, Global Initiative for Asthma, 2014, http://www.ginasthma.org/.

[2] G. P. Anderson, "Endotyping asthma: new insights into key pathogenic mechanisms in a complex, heterogeneous disease," The Lancet, vol. 372, no. 9643, pp. 1107-1119, 2008.

[3] http://www.who.int/mediacentre/factsheets/fs206/en/.

[4] M. Masoli, D. Fabian, S. Holt, and R. Beasley, "The global burden of asthma: executive summary of the GINA Dissemination Committee Report," Allergy, vol. 59, no. 5, pp. 469-478, 2004.

[5] S. D. Sullivan, S. E. Wenzel, B. W. Bresnahan et al., "Association of control and risk of severe asthma-related events in severe or difficult-to-treat asthma patients," Allergy, vol. 62, no. 6, pp. 655-660, 2007.

[6] K. Smith, T. Warholak, E. Armstrong, M. Leib, R. Rehfeld, and D. Malone, "Evaluation of risk factors and health outcomes among persons with asthma," Journal of Asthma, vol. 46, no. 3, pp. 234-237, 2009.

[7] L. Watson, F. Turk, P. James, and S. T. Holgate, "Factors associated with mortality after an asthma admission: a national United Kingdom database analysis," Respiratory Medicine, vol. 101, no. 8, pp. 1659-1664, 2007.

[8] I. Kola, “The state of innovation in drug development," Clinical Pharmacology \& Therapeutics, vol. 83, no. 2, pp. 227-230, 2008.

[9] S. M. Paul, D. S. Mytelka, C. T. Dunwiddie et al., "How to improve R\&D productivity: the pharmaceutical industry's grand challenge," Nature Reviews Drug Discovery, vol. 9, no. 3, pp. 203-214, 2010.

[10] M. H. Karol, "Animal models of occupational asthma," European Respiratory Journal, vol. 7, no. 3, pp. 555-568, 1994.

[11] G. R. Zosky and P. D. Sly, "Animal models of asthma," Clinical and Experimental Allergy, vol. 37, no. 7, pp. 973-988, 2007.

[12] I. Szelenyi, "Animal models of bronchial asthma," Inflammation Research, vol. 49, no. 12, pp. 639-654, 2000.

[13] P. Padrid, "Chronic lower airway disease in the dog and cat," Problems in Veterinary Medicine, vol. 4, no. 2, pp. 320-344, 1992.

[14] B. Herszberg, D. Ramos-Barbón, M. Tamaoka, J. G. Martin, and J.-P. Lavoie, "Heaves, an asthma-like equine disease, involves airway smooth muscle remodeling," The Journal of Allergy and Clinical Immunology, vol. 118, no. 2, pp. 382-388, 2006.

[15] S. D. Shapiro, "The use of transgenic mice for modeling airways disease," Pulmonary Pharmacology and Therapeutics, vol. 21, no. 5, pp. 699-701, 2008.

[16] D. M. Hyde, L. A. Miller, E. S. Schelegle et al., "Asthma: a comparison of animal models using stereological methods," European Respiratory Review, vol. 15, no. 101, pp. 122-135, 2006.
[17] J. G. Martin and D. Ramos-Barbón, "Airway smooth muscle growth from the perspective of animal models," Respiratory Physiology and Neurobiology, vol. 137, no. 2-3, pp. 251-261, 2003.

[18] A. M. Holmes, R. Solari, and S. T. Holgate, "Animal models of asthma: value, limitations and opportunities for alternative approaches," Drug Discovery Today, vol. 16, no. 15-16, pp. 659670, 2011.

[19] K. W. McGrath, N. Icitovic, H. A. Boushey et al., "Asthma Clinical Research Network of the National Heart, Lung, and Blood Institute. A large subgroup of mild-to-moderate asthma is persistently noneosinophilic," The American Journal of Respiratory and Critical Care Medicine, vol. 185, no. 6, pp. 612-619, 2012.

[20] S. T. Holgate, "Stratified approaches to the treatment of asthma," British Journal of Clinical Pharmacology, vol. 76, no. 2, pp. 277291, 2013.

[21] I. O. Agache, "From phenotypes to endotypes to asthma treatment," Current Opinion in Allergy and Clinical Immunology, vol. 13, no. 3, pp. 249-256, 2013.

[22] S. Wenzel, "Severe asthma: from characteristics to phenotypes to endotypes," Clinical and Experimental Allergy, vol. 42, no. 5, pp. 650-658, 2012.

[23] P. J. Barnes, "Severe asthma: advances in current management and future therapy," Journal of Allergy and Clinical Immunology, vol. 129, no. 1, pp. 48-59, 2012.

[24] C. S. Stevenson and M. A. Birrell, "Moving towards a new generation of animal models for asthma and COPD with improved clinical relevance," Pharmacology and Therapeutics, vol. 130, no. 2, pp. 93-105, 2011.

[25] R. A. Martin, S. R. Hodgkins, A. E. Dixon, and M. E. Poynter, "Aligning mouse models of asthma to human endotypes of disease," Respirology, vol. 19, no. 6, pp. 823-833, 2014.

[26] J. R. Johnson, R. E. Wiley, R. Fattouh et al., "Continuous exposure to house dust mite elicits chronic airway inflammation and structural remodeling," The American Journal of Respiratory and Critical Care Medicine, vol. 169, no. 3, pp. 378-385, 2004.

[27] L. McKinley, J. F. Alcorn, A. Peterson et al., "TH17 cells mediate steroid-resistant airway inflammation and airway hyperresponsiveness in mice," The Journal of Immunology, vol. 181, no. 6, pp. 4089-4097, 2008.

[28] S. Ano, Y. Morishima, Y. Ishii et al., "Transcription factors GATA-3 and ROR $\gamma$ t are important for determining the phenotype of allergic airway inflammation in a murine model of Asthma," The Journal of Immunology, vol. 190, no. 3, pp. 10561065, 2013.

[29] K. Ota, M. Kawaguchi, S. Matsukura et al., "Potential involvement of IL-17F in asthma," Journal of Immunology Research, vol. 2014, Article ID 602846, 8 pages, 2014.

[30] R. A. Martin, J. L. Ather, R. Daggett et al., "The endogenous Th17 response in $\mathrm{NO}_{2}$-promoted allergic airway disease is dispensable for airway hyperresponsiveness and distinct from Th17 adoptive transfer," PLoS ONE, vol. 8, no. 9, Article ID e74730, 2013.

[31] M. A. M. Willart, K. Deswarte, P. Pouliot et al., "Interleukin$1 \alpha$ controls allergic sensitization to inhaled house dust mite via the epithelial release of GM-CSF and IL-33," The Journal of Experimental Medicine, vol. 209, no. 8, pp. 1505-1517, 2012.

[32] S. K. Mazmanian and D. L. Kasper, "The love-hate relationship between bacterial polysaccharides and the host immune system," Nature Reviews Immunology, vol. 6, no. 11, pp. 849-858, 2006. 
[33] D. R. Ownby, C. C. Johnson, and E. L. Peterson, "Exposure to dogs and cats in the first year of life and risk of allergic sensitization at 6 to 7 years of age," The Journal of the American Medical Association, vol. 288, no. 8, pp. 963-972, 2002.

[34] M. Kalliomäki, P. Kirjavainen, E. Eerola, P. Kero, S. Salminen, and E. Isolauri, "Distinct patterns of neonatal gut microflora in infants in whom atopy was and was not developing," Journal of Allergy and Clinical Immunology, vol. 107, no. 1, pp. 129-134, 2001.

[35] S. Havstad, G. Wegienka, E. M. Zoratti et al., "Effect of prenatal indoor pet exposure on the trajectory of total IgE levels in early childhood," The Journal of Allergy and Clinical Immunology, vol. 128, no. 4, pp. 880-885, 2011.

[36] C. Braun-Fahrländer, J. Riedler, U. Herz et al., "Environmental exposure to endotoxin and its relation to asthma in school-age children," The New England Journal of Medicine, vol. 347, no. 12, pp. 869-877, 2002.

[37] M. J. Ege, M. Mayer, A.-C. Normand et al., "Exposure to environmental microorganisms and childhood asthma," The New England Journal of Medicine, vol. 364, no. 8, pp. 701-709, 2011.

[38] H. Bisgaard, N. Li, K. Bonnelykke et al., "Reduced diversity of the intestinal microbiota during infancy is associated with increased risk of allergic disease at school age," Journal of Allergy and Clinical Immunology, vol. 128, no. 3, pp. 646-652.e5, 2011.

[39] R. J. Martin, M. Kraft, H. W. Chu, E. A. Berns, and G. H. Cassell, "A link between chronic asthma and chronic infection," The Journal of Allergy and Clinical Immunology, vol. 107, no. 4, pp. 595-601, 2001.

[40] A. Kocabas, M. Avsar, I. Hanta, F. Koksal, and S. Kuleci, "Chlamydophila pneumoniae infection in adult asthmatics patients," Journal of Asthma, vol. 45, no. 1, pp. 39-43, 2008.

[41] K. Specjalski and E. Jassem, "Chlamydophila pneumoniae, Mycoplasma pneumoniae infections, and asthma control," Allergy and Asthma Proceedings, vol. 32, no. 2, pp. 9-17, 2011.

[42] H. Bisgaard, M. N. Hermansen, F. Buchvald et al., "Childhood asthma after bacterial colonization of the airway in neonates," The New England Journal of Medicine, vol. 357, no. 15, pp. 14871495, 2007.

[43] M. Hilty, C. Burke, H. Pedro et al., "Disordered microbial communities in asthmatic airways," PLoS ONE, vol. 5, no. 1, Article ID e8578, 2010.

[44] Y. J. Huang, C. E. Nelson, E. L. Brodie et al., "Airway microbiota and bronchial hyperresponsiveness in patients with suboptimally controlled asthma," Journal of Allergy and Clinical Immunology, vol. 127, no. 2, pp. 372-381.e3, 2011.

[45] M. L. Sogin, H. G. Morrison, J. A. Huber et al., "Microbial diversity in the deep sea and the underexplored 'rare biosphere"' Proceedings of the National Academy of Sciences of the United States of America, vol. 103, no. 32, pp. 12115-12120, 2006.

[46] K. E. Nelson, G. M. Weinstock, S. K. Highlander et al., "Human microbiome jumpstart reference strains consortium. A catalog of reference genomes from the human microbiome," Science, vol. 328, pp. 994-999, 2010.

[47] A. C. Ouwehand, E. Isolauri, F. He, H. Hashimoto, Y. Benno, and S. Salminen, "Differences in Bifidobacterium flora composition in allergic and healthy infants," Journal of Allergy and Clinical Immunology, vol. 108, no. 1, pp. 144-145, 2001.

[48] C. Vael, V. Nelen, S. L. Verhulst, H. Goossens, and K. N. Desager, "Early intestinal Bacteroides fragilis colonisation and development of asthma," BMC Pulmonary Medicine, vol. 8, article 19, 2008.
[49] G. B. Rogers, M. P. Carroll, D. J. Serisier, P. M. Hockey, G. Jones, and K. D. Bruce, "Characterization of bacterial community diversity in cystic fibrosis lung infections by use of $16 \mathrm{~S}$ ribosomal DNA terminal restriction fragment length polymorphism profiling," Journal of Clinical Microbiology, vol. 42, no. 11, pp. 5176-5183, 2004.

[50] J. K. Harris, M. A. De Groote, S. D. Sagel et al., "Molecular identification of bacteria in bronchoalveolar lavage fluid from children with cystic fibrosis," Proceedings of the National Academy of Sciences of the United States of America, vol. 104, no. 51, pp. 20529-20533, 2007.

[51] E. S. Charlson, K. Bittinger, A. R. Haas et al., "Topographical continuity of bacterial populations in the healthy human respiratory tract," American Journal of Respiratory and Critical Care Medicine, vol. 184, no. 8, pp. 957-963, 2011.

[52] Y. J. Huang, E. Kim, M. J. Cox et al., "A persistent and diverse airway microbiota present during chronic obstructive pulmonary disease exacerbations," OMICS, vol. 14, no. 1, pp. 959, 2010.

[53] J. R. Erb-Downward, D. L. Thompson, M. K. Han et al., "Analysis of the lung microbiome in the 'healthy' smoker and in COPD," PLoS ONE, vol. 6, no. 2, Article ID e16384, 2011.

[54] M. C. Abt and D. Artis, "The intestinal microbiota in health and disease: the influence of microbial products on immune cell homeostasis," Current Opinion in Gastroenterology, vol. 25, no. 6, pp. 496-502, 2009.

[55] K. E. Fujimura, N. A. Slusher, M. D. Cabana, and S. V. Lynch, "Role of the gut microbiota in defining human health," Expert Review of Anti-Infective Therapy, vol. 8, no. 4, pp. 435-454, 2010.

[56] R. M. McLoughlin and K. H. G. Mills, "Influence of gastrointestinal commensal bacteria on the immune responses that mediate allergy and asthma," The Journal of Allergy and Clinical Immunology, vol. 127, no. 5, pp. 1097-1107, 2011.

[57] A. L. Kozyrskyj, S. Bahreinian, and M. B. Azad, "Early life exposures: impact on asthma and allergic disease," Current Opinion in Allergy and Clinical Immunology, vol. 11, no. 5, pp. 400-406, 2011.

[58] J. L. Round, R. M. O'Connell, and S. K. Mazmanian, "Coordination of tolerogenic immune responses by the commensal microbiota," Journal of Autoimmunity, vol. 34, no. 3, pp. J220J225, 2010.

[59] B. Schaub, J. Liu, S. Höppler et al., "Maternal farm exposure modulates neonatal immune mechanisms through regulatory $\mathrm{T}$ cells," The Journal of Allergy and Clinical Immunology, vol. 123, no. 4, pp. 774-782, 2009.

[60] E. Mileti, G. Matteoli, I. D. Iliev, and M. Rescigno, "Comparison of the immunomodulatory properties of three probiotic strains of Lactobacilli using complex culture systems: prediction for in vivo efficacy," PLoS ONE, vol. 4, no. 9, Article ID e7056, 2009.

[61] Y. J. Huang, "Asthma microbiome studies and the potential for new therapeutic strategies," Current Allergy and Asthma Reports, vol. 13, no. 5, pp. 453-461, 2013.

[62] D. L. Hahn, R. W. Dodge, and R. Golubjatnikov, "Association of Chlamydia pneumoniae (strain TWAR) infection with wheezing, asthmatic bronchitis, and adult-onset asthma," The Journal of the American Medical Association, vol. 266, no. 2, pp. 225-230, 1991.

[63] P. R. Marri, D. A. Stern, A. L. Wright, D. Billheimer, and F. D. Martinez, "Asthma-associated differences in microbial composition of induced sputum," The Journal of Allergy and Clinical Immunology, vol. 131, no. 2, pp. 346-e3, 2013. 
[64] Y. Tomosada, E. Chiba, H. Zelaya et al., "Nasally administered Lactobacillus rhamnosus strains differentially modulate respiratory antiviral immune responses and induce protection against respiratory syncytial virus infection," BMC Immunology, vol. 14, no. 1, article 40, 2013.

[65] H. C. Van Woerden, C. Gregory, R. Brown, J. R. Marchesi, B. Hoogendoorn, and I. P. Matthews, "Differences in fungi present in induced sputum samples from asthma patients and nonatopic controls: a community based case control study," BMC Infectious Diseases, vol. 13, no. 1, article 69, 2013.

[66] G. Gaitanis, P. Magiatis, M. Hantschke, I. D. Bassukas, and A. Velegraki, "The Malassezia genus in skin and systemic diseases," Clinical Microbiology Reviews, vol. 25, no. 1, pp. 106-141, 2012.

[67] T. Olszak, D. An, S. Zeissig et al., "Microbial exposure during early life has persistent effects on natural killer T cell function," Science, vol. 336, no. 6080, pp. 489-493, 2012.

[68] T. Herbst, A. Sichelstiel, C. Schär et al., "Dysregulation of allergic airway inflammation in the absence of microbial colonization," American Journal of Respiratory and Critical Care Medicine, vol. 184, no. 2, pp. 198-205, 2011.

[69] S. L. Russell, M. J. Gold, M. Hartmann et al., "Early life antibiotic-driven changes in microbiota enhance susceptibility to allergic asthma," EMBO Reports, vol. 13, no. 5, pp. 440-447, 2012.

[70] K. Karimi, M. D. Inman, J. Bienenstock, and P. Forsythe, "Lactobacillus reuteri-induced regulatory $\mathrm{T}$ cells protect against an allergic airway response in mice," American Journal of Respiratory and Critical Care Medicine, vol. 179, no. 3, pp. 186193, 2009.

[71] J. MacSharry, C. O’Mahony, K. H. Shalaby et al., "Immunomodulatory effects of feeding with Bifidobacterium longum on allergen-induced lung inflammation in the mouse," Pulmonary Pharmacology and Therapeutics, vol. 25, no. 4, pp. 325-334, 2012.

[72] H. Harb, E. A. F. van Tol, H. Heine et al., "Neonatal supplementation of processed supernatant from Lactobacillus rhamnosus GG improves allergic airway inflammation in mice later in life," Clinical and Experimental Allergy, vol. 43, no. 3, pp. 353-364, 2013.

[73] B. Zhang, J. An, T. Shimada, S. Liu, and K. Maeyama, "Oral administration of Enterococcus faecalis FK-23 suppresses Th17 cell development and attenuates allergic airway responses in mice," International Journal of Molecular Medicine, vol. 30, no. 2, pp. 248-254, 2012.

[74] C. Ai, Q. Zhang, C. Ren et al., "Genetically engineered Lactococcus lactis protect against house dust mite allergy in a BALB/c mouse model," PLoS ONE, vol. 9, no. 10, Article ID e109461, 2014.

[75] H. Kim, H. K. Kang, J. Cho et al., "Heat shock protein X purified from Mycobacterium tuberculosis enhances the efficacy of dendritic cells-based immunotherapy for the treatment of allergic asthma," BMB Reports, vol. 48, no. 3, pp. 178-183, 2015.

[76] M. M. P. Acencio, A. Perini, O. C. M. Ibanez et al., "The effect of BCG on the allergic response to ovalbumin in genetically selected strains of mice (IV-A)," Revista Brasileira de Alergia e Imunopatologia, vol. 26, pp. 134-145, 2003.

[77] X. Ke, J. Huang, Q. Chen, S. Hong, and D. Zhu, "Protective effects of combined Mycobacterium bovis BCG and interleukin12 vaccination on airway inflammation in a murine model of allergic asthma," Clinical and Investigative Medicine, vol. 33, no. 3, pp. e196-e202, 2010.

[78] C. Hartmann, A. Behrendt, S. Henken, F. Wölbeling, U. A. Maus, and G. Hansen, "Pneumococcal pneumonia suppresses allergy development but preserves respiratory tolerance in mice," Immunology Letters, vol. 164, no. 1, pp. 44-52, 2015.

[79] H. Evans and E. Mitre, "Worms as therapeutic agents for allergy and asthma: understanding why benefits in animal studies have not translated into clinical success," Journal of Allergy and Clinical Immunology, vol. 135, no. 2, pp. 343-353, 2014.

[80] E. S. Gollwitzer, S. Saglani, A. Trompette et al., "Lung microbiota promotes tolerance to allergens in neonates via PD-L1," Nature Medicine, vol. 20, no. 6, pp. 642-647, 2014. 


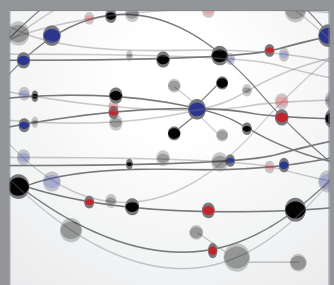

The Scientific World Journal
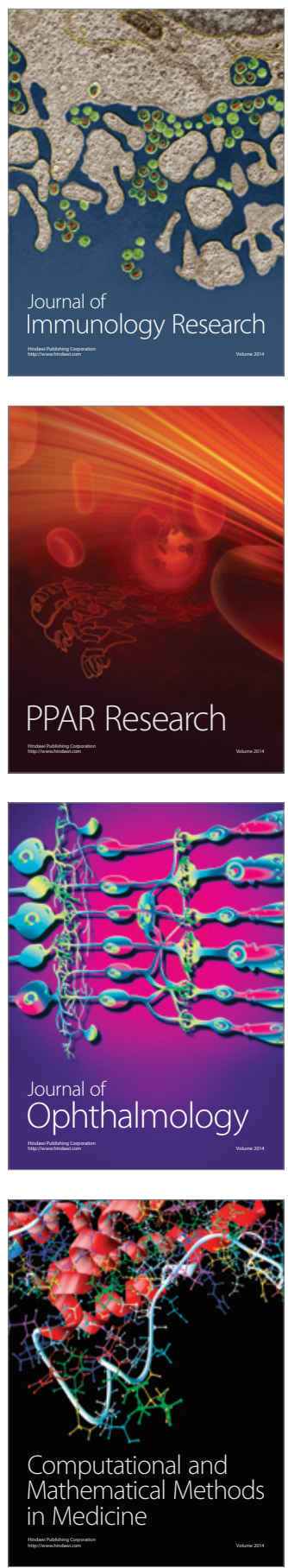

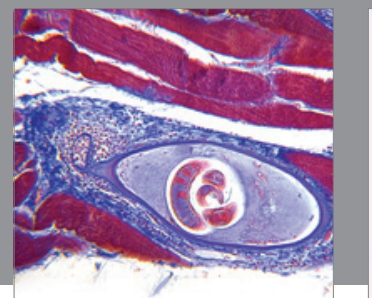

Gastroenterology

Research and Practice
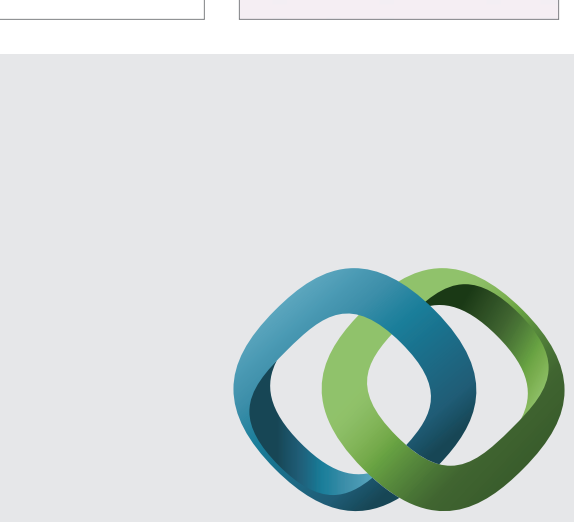

\section{Hindawi}

Submit your manuscripts at

http://www.hindawi.com
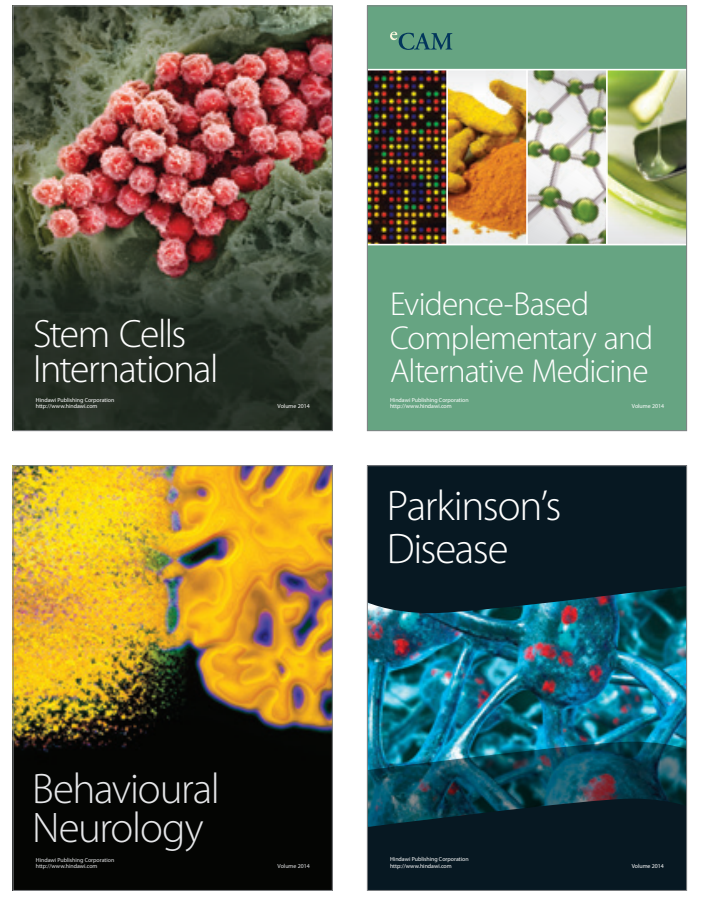
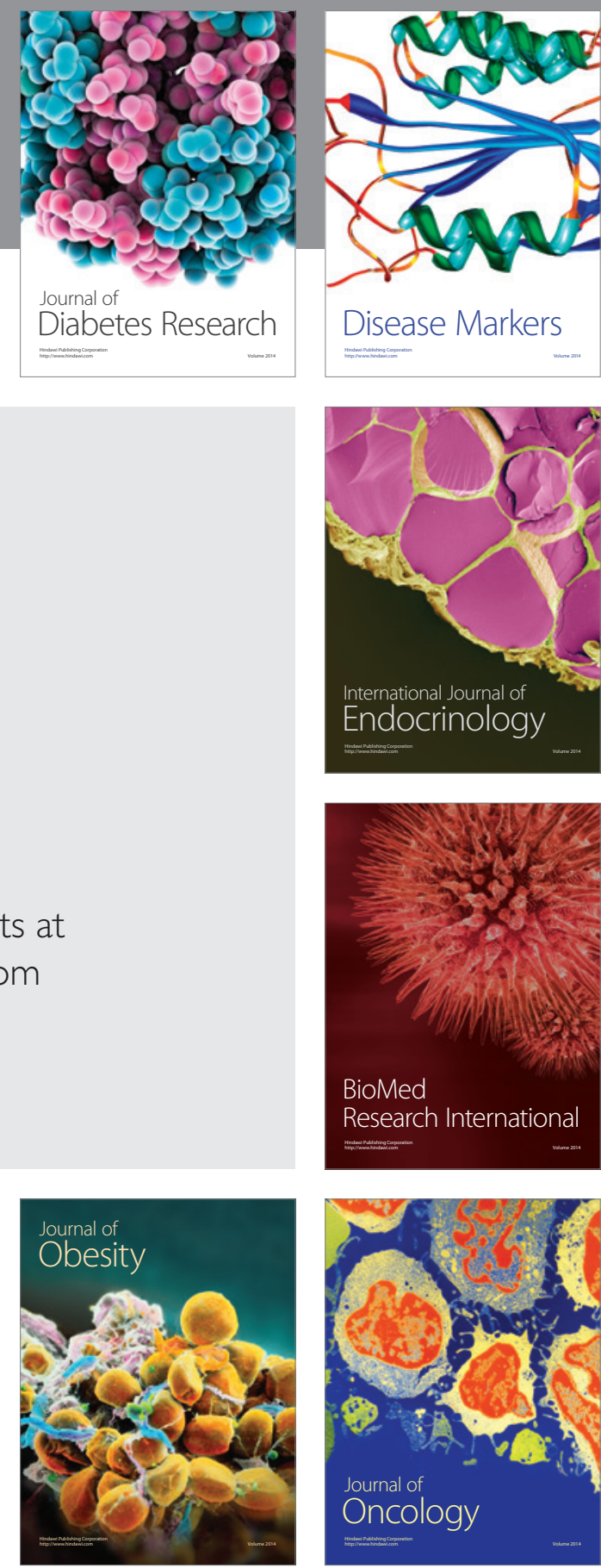

Disease Markers
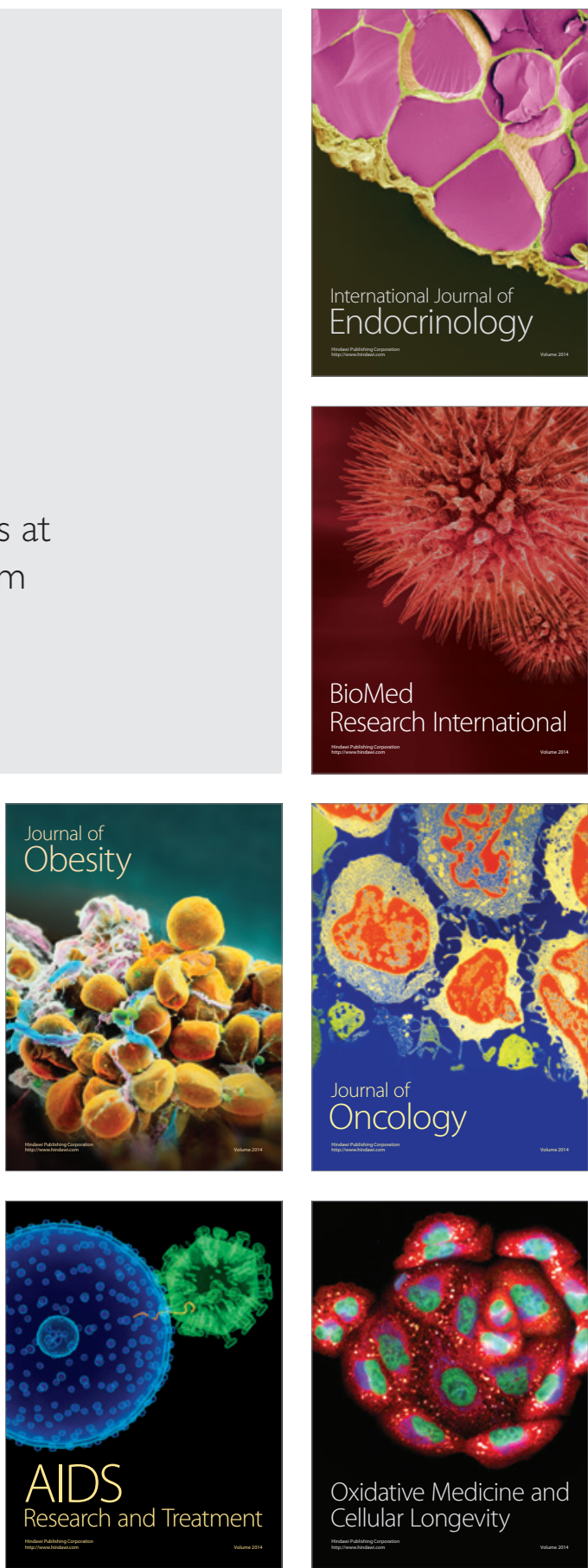